\title{
Pore-Structure-Based Determination of Unsaturated Hygric Properties of Porous Materials *
}

\author{
Muhammad Islahuddin \\ Hans Janssen \\ KU Leuven, Department of Civil Engineering, Building Physics Section, Kasteelpark \\ Arenberg 40, 3001 Leuven, Belgium
}

\author{
Received: 24 August 2018 / Accepted: 29 August 2019
}

\begin{abstract}
A reliable and practical method of hygric property characterisation is a major determinant in properly analysing hygric performance of built constructions. The current empirical approach however yields data that are still incomplete, not fully representative, and not entirely reliable. In this study, hygric properties are therefore determined directly from pore structure information by applying stationary unsaturated pore-scale physics to model moisture storage and transport. The pore space is captured by visualisation techniques and further extracted into a discrete network of variably shaped pore bodies interconnected by pore throats. In this network, corner and surface adsorption and capillary condensation are simulated to define the moisture storage. Air entrapment is furthermore considered to determine the capillary moisture content. The resulting spatial moisture distribution in the pore network allows moisture to flow, in wet elements in the liquid phase and in dry elements in the vapour phase. The absorbed corner and surface films moreover enable additional liquid flow. These various simultaneous flows aggregately define the transport property. A comparison to measured data validates the presented hygric property model.

Keywords - hygric properties moisture retention curve moisture permeability curve pore-network model unsaturated flow porous materials
\end{abstract}

\section{Introduction}

The hydraulic properties of the porous medium are essential determinants for assessing the storage and flow of fluids in porous materials. In relation to the durability and sustainability of the built environment, the hygric properties of building materials are crucial factors to accurately analyse or design the moisture performances of built structures. These accurate evaluations can prevent moisture-related problems, such as mould growth due to excessive interior humidity or rebar corrosion owing to chloride infiltration via pore water. This prevention, in turn, creates sustainable and durable built structures, which ensure the health and comfort of their human users. Therefore, a reliable and practical characterisation method for the hygric properties of building materials is highly desirable.

These hygric properties are the unsaturated moisture storage and transport properties, determining the impact of moisture on building materials. They are commonly represented by the moisture retention and permeability curves, which show the relationship between capillary pressure and, respectively, 5 moisture content and moisture permeability (Roels et al. 2003b), hence depicting the entire unsaturated moisture response of the material. These storage and transport properties are commonly measured through a series of repetitive experiments on several samples at various conditions separately. To determine the moisture retention curve, for example, results from standard desiccator, pressure plate, and vacuum saturation tests have to be combined, since they all provide data at different conditions (Roels

40 et al. 2004b; Feng et al. 2015). As a result, the current acquisition procedure requires a substantial amount of effort and time, and thus is not very efficient.

The resulting measured data, moreover, are not entirely reliable nor complete nor representative. As reported in Roels et al. (2004b), round-robin measurements of basic hygric properties based on European Standards conducted by several institutions in Europe yield notable variations, in general

\footnotetext{
*This research is supported by the Research Foundation - Flanders (FWO) Odysseus grant "Moisture transfer in building materials: analysis at the pore-scale level".
} 
Postprint: Islahuddin M. and Janssen H. 2019. Pore-structure-based determination of unsaturated hygric properties of porous materials. Transp Porous Med, 130:675.

https://doi.org/10.1007/s11242-019-01334-7

45 due to equipment differences, specimen handling, data collection, and data interpretation. Furthermore, results can only be obtained for a limited range of saturation conditions, and they therefore do not cover the whole moisture content range (Carmeliet and Roels 2001, 2002; Carmeliet et al. 2004; Roels et al. 2004a,b; Scheffler and Plagge 2010; Feng et al. 2015). Finally, the experimental procedures combine ad- and desorption processes as well as static and dynamic methods, thus (partially) ignoring storage hysteresis, air entrapment, and dynamic effects (Janssen et al. 2016).

These above-mentioned deficiencies of the current empirical property characterisation can be resolved by determining the hygric properties directly from pore structure information. Such a direct determination is intuitively promising, as macroscopic moisture properties are aggregately governed by the pore-scale physics of moisture storage and transport taking place in the pore space of porous materi-

55 als. Moreover, this pore-scale modelling has gained popularity in many research areas, among others in petroleum reservoir rocks (Sahimi 1993; Valvatne et al. 2005; Piri and Blunt 2005), hydrogen fuel cells (Qin 2015; Gostick et al. 2007), and porous material drying (Prat 2011; Yiotis et al. 2006; Vorhauer et al. 2010).

In building physics applications, such approaches have already been applied to determine the moisture ${ }_{60}$ transport property (Quenard and Sallee 1992; Descamps 1997; Carmeliet et al. 1999). These studies generally modelled a complex pore structure as a regular lattice, of (sometimes volumeless) spherical pore bodies interconnected by tubular pore throats. As this regular lattice defined the pore position and connectivity, the pore space was highly simplified, ignoring the real geometry and topology. Many studies, however, have shown the importance of these two for fluid transport properties (Chatzis and 65 Dullien 1977; Jerauld et al. 1984; Parlar and Yortsos 1988; Jivkov et al. 2013). Moreover, in these models the geometrical pore shape was commonly simplified to circular cross-sections (Descamps 1997), which completely neglects pore crevices in which moisture can condensate at low relative humidity, thus allowing transport in liquid form. For the assumed pore shape, a pore radius distribution was calculated from a measured pore volume distribution, which was the main empirical input to design the network models. However, as values for other geometrical parameters, such as pore shape factor and pore tube length, were derived from assumptions, the model was also geometrically not representative. This is in contrast to the findings that the geometrical features also define the fluid transport properties (Vogel and Roth 2001). Therefore, besides a measured moisture storage function (or pore volume distribution), such models moreover required calibration to measured permeabilities at hygroscopic and saturated conditions (Carmeliet et al. 1999; Carmeliet and Roels 2001).

This study is therefore devoted to progressing the pore-structure-based numerical simulation of hygric properties for unsaturated moisture transfer in porous building materials. The improvements of the presented model, relative to the current praxis in building physics, are threefold: the pore-network model is topologically and geometrically representative of the real pore space; the storage and transport so properties are calculated simultaneously without a need for input of storage data nor for calibration to permeability data; and the resulting properties are complete. The added value of the presented model in relation to general pore-network models is the focus on unsaturated moisture transfer, with storage and transport in the liquid and vapour phase simultaneously.

The remainder of this paper is organised as follows. Section 2 discusses the presented model consisting

${ }_{85}$ of the pore-network models and the pore-scale physics involved. The subsequent section elaborates the application of the model to two rock samples, followed by a validation on a sintered-glass filter. The final section summarises this study with conclusions.

It can be noted that neither the application nor the validation section makes use of an actual building material. A substitute material, whose pore size distribution lies in the center of the pore size range 90 typical for building materials, is used instead. This is a consequence of the current restrictions on pore network characterisation for porous building materials, which do not permit yet to characterise the complete pore structure of porous building materials, typically spanning pore sizes from nanometer to millimeter. The unsaturated storage and transport of water and vapour simultaneously is however strongly related to applications in building materials, and such will be further studied once their pore

95 networks become available. That is the topic of currently ongoing research though and hence is matter for future publications. 
Postprint: Islahuddin M. and Janssen H. 2019. Pore-structure-based determination of unsaturated hygric properties of porous materials. Transp Porous Med, 130:675.

https://doi.org/10.1007/s11242-019-01334-7

\section{Pore-scale modelling}

In this study, the moisture storage and transport properties are numerically determined directly from the microstructural characterisation of the material's pore space. The pore structure is represented by a network of discrete pore bodies and pore throats, wherein the pore throats are each connecting two neighbouring pore bodies. The pore bodies and pore throats (or simply: pore elements) are conceptualized by tubular shapes, with various simplified cross-sectional forms. This approach in representing the void pore space is called the pore-network model (PNM).

In these PNMs, the steady-state spatial moisture distributions at a specific ambient condition are first determined by an invasion algorithm, which aims at replicating the actual moisture storage processes during adsorption, desorption, imbibition, or drainage. These four macroscopic processes are simulated in this study, and are driven by microscopic behaviours at the pore-scale. The microscopic interaction between the water vapour molecules and the capillary walls results in adsorbed liquid water on the pore walls and in the pore corners. If a threshold capillary pressure is achieved, the vapour molecules condense and fill the pore center with liquid water. Additionally, capillary suction via neighbouring filled pores may also fill the pore with water. Over the whole capillary pressure range, the moisture distribution governed by the above-mentioned pore-scale behaviours is evolved in equilibrium with the invasion process and the boundary conditions, and finally determines the moisture retention curve. Subsequently, the moisture permeability curve is determined by calculating, for each moisture distribution, the inlet-to-outlet flow in the network upon imposing an infinitesimal pressure difference over the PNM, wherein the moisture flows in liquid and vapour phases are accounted for simultaneously.

\subsection{Pore-network model}

An image-based PNM (as used in this study) preserves the real topological and geometrical properties of a pore space. This can be achieved by reconstructing a three-dimensional voxelized image captured by, for example, an X-ray microcomputed tomography (micro-CT). Subsequent to thresholding into a binary image, an extraction algorithm is executed to model the complex pore space by a network of pore bodies and pore throats with elementary geometrical forms. In principle, after determining the porosity, the extraction process first preserves the topological property by defining the pore connectivity through, for example, a medial-axis skeleton (Baldwin et al. 1996; Lindquist et al. 1996) or clusters of maximal and pore throats, followed by determining their geometrical properties (e.g. volume, inscribed radius, length). The volume and length, for instance, are determined by counting the number of voxels of the corresponding quantity designated in a pore element. Such network extraction processes conserve the topological properties as well as the main geometrical features, subject to the limitation of the image resolution. The three-dimensional visualization of the extracted PNMs for a sandstone and a carbonate are shown in Figure 1.

The main feature of a PNM is its geometrical simplicity enabling a flow calculation through a simple channel. The PNM extraction of Dong and Blunt (2009) is primarily used in this study, in which a pore element is modelled by a tubular shape with a constant cross-sectional geometry. The cross-sectional shapes are characterized from the voxelized image and parametrized into a dimensionless parameter, the so-called shape factor $G[-]$ defined as (Mason and Morrow 1991):

$$
G=\frac{A}{p^{2}}
$$

with $A\left[\mathrm{~m}^{2}\right]$ the cross-section area and $p[\mathrm{~m}]$ its corresponding perimeter length. This parameter is the appropriate shape factor formulation obtained when deriving the breakthrough curvature radius based on the Mayer-Stowe-Princen (MS-P) method (Mayer and Stowe 1965; Princen 1969a,b, 1970). Capillary behaviours of tubes with varying cross-sectional shapes can be characterized by this shape factor $G$, which classifies the pore cross-section into circular, square, or triangular shapes. The shape factors of a circle and square are $1 /(4 \pi)$ and $1 / 16$, respectively. For a triangle, the shape factor ranges from 0 for a slit-shaped triangle to $\sqrt{3} / 36$ for an equilateral triangle. 
(a)

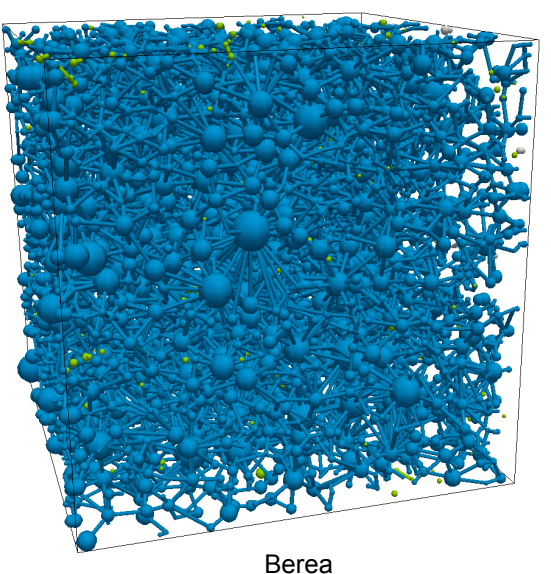

(b)

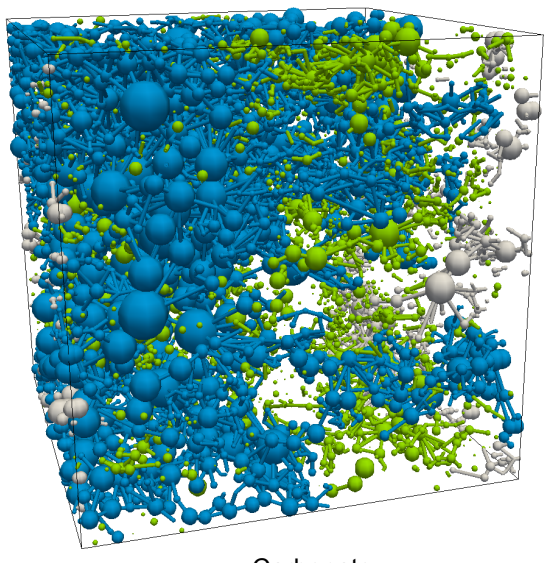

Carbonate

Figure 1: PNMs of (a) Berea sandstone and (b) Carbonate. Each network may consist of a collection of pores and throats that connect inlet and outlet (spanning cluster: blue), are only connected to either inlet or outlet (surface cluster: white), and are not connected to inlet and outlet (isolated cluster: green). In contrast to the uniformly sized cylinders, the shown spheres are sized by the inscribed radius; please note that more complex and complete geometrical properties are used in the actual simulations.

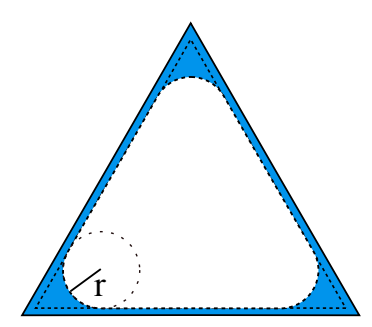

Air

Water

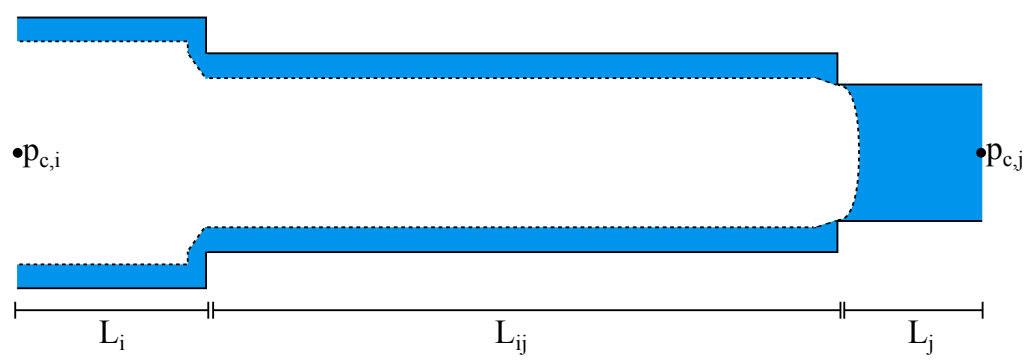

Figure 2: (a) Corner and surface water configuration in a triangular cross-section at the capillary pressure related to the curvature radius r. (b) Bulk vapour, bulk and surface liquid configuration in an axial crosssection of a conduit $i j$ : half pore body $i$, pore throat $i j$, and half pore body $j$. The capillary pressures $p_{c, i}$ and $p_{c, j}$ are at the center of the related pore bodies with lengths $L_{i}$ and $L_{j}$, respectively.

\subsection{Unsaturated hygric properties}

\subsubsection{Moisture invasion algorithms}

\section{Microscopic processes: capillary condensation, corner and surface adsorptions}

Moisture invasions are based on the following pore-scale phenomena: capillary condensation, corner adsorption, and surface adsorption. Their spatial configuration in a pore cross-section is shown in Figure 2. The invasion processes are formulated based on the capillary pressure $p_{c}[\mathrm{~Pa}]$ defined by the Kelvin

$$
p_{c}=\rho_{l} R_{v} T \ln \varphi
$$

with $\varphi[-]$ the air's relative humidity, $\rho_{l}\left[\mathrm{~kg} / \mathrm{m}^{3}\right]$ water liquid density, $R_{v}[\mathrm{~J} / \mathrm{kgK}]$ vapour gas constant, and $T[\mathrm{~K}]$ temperature.

Capillary condensation occurs if the pore's threshold capillary pressure has been exceeded. This threshold capillary pressure corresponds to the radius of the biggest inscribed sphere in a pore element, and, for cylindrical tubes, it is described by Young-Laplace's equation (Mayer and Stowe 1965; Princen 1969a,b, 1970):

$$
p_{c}^{*}=\frac{-2 \sigma \cos \theta}{r}=p_{l}-p_{g}
$$

with $p_{c}^{*}[\mathrm{~Pa}]$ threshold capillary pressure, $\theta[\mathrm{rad}]$ contact angle, $\sigma[\mathrm{N} / \mathrm{m}]$ surface tension, $r[\mathrm{~m}]$ the inscribed radius, and $p_{l}$ and $p_{g}[\mathrm{~Pa}]$ liquid and gas pressures respectively. This formula states that the threshold capillary pressure is proportional to the inscribed radius. For general cross-section shapes, as 
Postprint: Islahuddin M. and Janssen H. 2019. Pore-structure-based determination of unsaturated hygric properties of porous materials. Transp Porous Med, 130:675.

https://doi.org/10.1007/s11242-019-01334-7 1997):

$$
p_{c}^{*}=\frac{-(1+2 \sqrt{\pi G}) \sigma \cos \theta}{r} .
$$

Note that Eq. 4 is equal to Eq. 3 for pores with circular cross-section.

At capillary pressures smaller than the threshold value, adsorbed water vapour molecules accumulate at pore corners and form menisci with a curvature radius $r_{c}$ as a function of the capillary pressure. The volume saturation of these water corners, $S_{c}[-]$, can be derived geometrically and reveals to be dependent on the pore shape as well as the capillary pressure (Mason and Morrow 1991):

$$
S_{c}= \begin{cases}0 & , \text { circular shapes } \\ \frac{(4-\pi) r_{c}\left(p_{c}\right)^{2}}{A(G)} & , \text { square shapes } \\ (1-4 \pi G)\left(\frac{r_{c}\left(p_{c}\right)}{2 G p}\right)^{2} & , \text { triangular shapes }\end{cases}
$$

with $A(G)\left[\mathrm{m}^{2}\right]$ cross-sectional area, $p[\mathrm{~m}]$ perimeter length, and $r_{c}\left(p_{c}\right)[\mathrm{m}]$ curvature radius as defined by Eq. 3. The corner saturation $S_{c}$ quantifies the fraction of the occupied corner volume relative to the overall pore volume.

In addition to corner adsorption, water vapour molecules are equally adsorbed onto the pore wall, leading to the formation of a water surface film. The amount of water present is quantified by its thickness, $t_{f}[\mathrm{~nm}]$, based on Bradley's statistical thickness (Badmann et al. 1981):

$$
t_{f}\left(p_{c}\right)=\left[K_{1}+K_{2} \ln \left(-\frac{p_{c}}{\rho_{l} R_{v} T}\right)\right] .
$$

This statistical thickness was formulated based on gravimetric measurement of adsorption experiments which were performed on hydrophilic materials of unhydrated calcium silicates and raw Portland cements.

empirical correlation Eq. 6 was then derived from the resulting averaged Brunauer-Emmett-Teller (BET) isotherms and was shown to be more accurate than the Frankel-Halsey-Hill (FHH) theory for the entire relative humidity range. The two material parameters were determined as $K_{1}=0.385$ and $K_{2}=-0.189$ for silicate based materials (Badmann et al. 1981). Taking this surface adsorption into account, moreover, results in a slight constriction of the cross-sectional area, and thus slightly decreases the threshold capillary pressure.

\section{Macroscopic processes: adsorption, desorption, imbibition, and drainage}

The above-mentioned pore-scale processes aggregately determine the macroscopic moisture invasions depending on the considered boundary conditions. Four moisture invasion algorithms are developed to mimic the corresponding experiments of water-vapour-air systems. They are adsorption, desorption, Table 1 .

Firstly, an adsorption algorithm is developed to model the invasion of water vapour as occurring in the standard desiccator test. At lower capillary pressures, equivalent to low relative humidities, water vapour molecules form mono/multilayer water adsorption on pore walls and condense into pore corners. For higher capillary pressures or relative humidities, this adsorption algorithm also simulates the bulk condensation of water vapour, because of capillary forces, if the threshold capillary pressure of a particular pore is achieved.

Secondly, contrary to the adsorption algorithm, a desorption algorithm reverses the adsorption process. This desorption algorithm simulates the evaporation process of pore water in contact with less humid ambient air. As capillary pressure decreases, bulk pore water is evaporated when the capillary pressure falls below the threshold capillary pressure. The threshold capillary pressure is assumed to be the same as that of adsorption. In addition to this local condition, the emptying pore must be connected to the ambient atmosphere at the network's boundaries via a continuous air path. Further evaporation reduces the condensed water in the pore corners and the adsorbed water on the pore walls.

Thirdly, the water uptake experiment is simulated by a quasi-static imbibition algorithm (Wilkinson and Willemsen 1983). A quasi-static approach is taken towards the invasion process, and no dynamic pore filling mechanisms (snap-off, cooperative pore filling, ...) are taken into account: pores are hence completely filled with water or with air. For the invasion mechanisms, pore body and throat sizes are both used. As the lateral sides are kept impermeable to prevent multidimensional flow, water liquid 
Postprint: Islahuddin M. and Janssen H. 2019. Pore-structure-based determination of unsaturated hygric properties of porous materials. Transp Porous Med, 130:675.
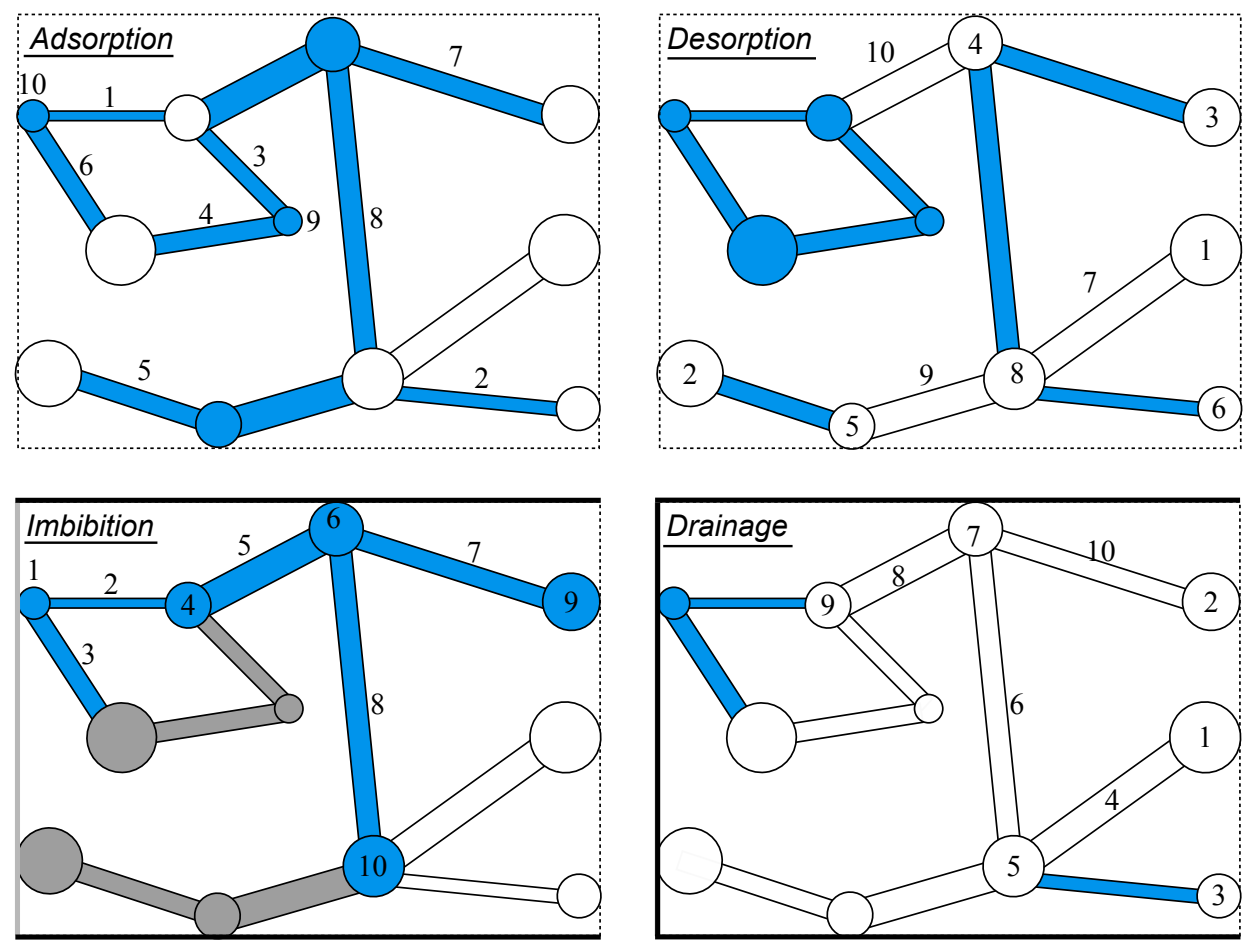

Fluid:

Boundary:

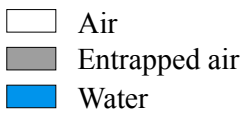

$$
\begin{array}{ll}
\cdots-. . & \text { Air } \\
\text { - } & \text { Water reservoir } \\
\text { — Impermeable }
\end{array}
$$

Figure 3: Invasion algorithms in a simple artificial two-dimensional PNM. The designated numbers show the first ten invasion orders of each invasion algorithm.

\begin{tabular}{|c|c|c|c|c|c|c|}
\hline \multirow{2}{*}{ Step (n) } & \multicolumn{2}{|c|}{ Adsorption } & \multicolumn{2}{|c|}{ Imbibition } & \multicolumn{2}{|c|}{ Drainage } \\
\hline & Pressure & Volume & Pressure & Volume & Pressure & Volume \\
\hline 1 & $p_{c, 1}$ & \multirow{10}{*}{$\sum_{i=1}^{n} V_{i}$} & & \multirow{10}{*}{$\sum_{i=1}^{n} V_{i}$} & $p_{c, 1}$ & \multirow{10}{*}{$V_{0}-\sum_{i=1}^{n} V_{i}$} \\
\hline 2 & $p_{c, 2}$ & & $p_{c, 1}$ & & $p_{c, 2}$ & \\
\hline 3 & $p_{c, 3}$ & & & & $p_{c, 3}$ & \\
\hline 4 & $p_{c, 4}$ & & & & & \\
\hline 5 & $p_{c, 5}$ & & $p_{c, 4}$ & & $p_{c, 4}$ & \\
\hline 6 & $p_{c, 6}$ & & & & & \\
\hline 7 & $p_{c, 7}$ & & $p_{c, 6}$ & & & \\
\hline 8 & $p_{c, 8}$ & & & & $p_{c, 6}$ & \\
\hline 9 & $p_{c, 9}$ & & $p_{c, 9}$ & & & \\
\hline 10 & $p_{c, 10}$ & & $p_{c, 10}$ & & $p_{c, 10}$ & \\
\hline
\end{tabular}

Table 1: Capillary pressure - moisture content relation of the invasion algorithms shown in Figure 3. The desorption pressure steps are similar to those of the adsorption.

$p_{c, i}$ is the capillary pressure at step i, which corresponds to the pore size of the designated invasion orders as shown in Figure 3. The volume $\mathrm{V}_{\mathrm{i}}$ considers only the pore water with $\mathrm{V}_{0}$ is the initial volume, which can be the volume at capillary or saturated moisture content. 
Postprint: Islahuddin M. and Janssen H. 2019. Pore-structure-based determination of unsaturated hygric properties of porous materials. Transp Porous Med, 130:675.

https://doi.org/10.1007/s11242-019-01334-7 occurs at the elements in contact with the water front. Among these elements, water first invades the smallest one, which has the smallest threshold capillary pressure. This single invasion then modifies the water front profile and its adjacent air-filled elements. The same procedure is applied recursively until the capillary moisture content is reached. However, the front water cannot invade a pore if the mechanism makes the entrapped air remain in the pore due to the assumptions of air incompressibility and immiscibility. Note that, as the water uptake experiment is by nature a dynamic process, an equilibrium moisture content will never be achieved except at the capillary moisture content. The imbibition moisture retention curve is therefore defined as a monotonically increasing function of the capillary pressure. For total moisture content are recorded. The following invasions occurred at smaller capillary pressures are accumulated to the previous invasion; increasing the moisture content of the previously recorded capillary pressure.

Finally, similar to desorption versus adsorption, the water drainage algorithm simulates the inverse process of the water uptake. However, the outlet of this drainage is only at one side, which limits the exposure of pore water to the ambient atmosphere. Apart to that, the withdrawal process of pore water is the same as the desorption algorithm.

Every invasion algorithm defines moisture distributions over the whole capillary pressure range. Each instance of these moisture distributions specifies the water-filled elements and the amount of corner and surface water in non-water-filled elements. As the element volumes are conserved, the moisture content at every capillary pressure is calculated from the aggregate volume of the wet pores, and of the corner and surface water. The amount of moisture from the vapour phase is very small and thus is neglected. This unique relation between the capillary pressure and the moisture content forms the so-called moisture retention curve.

\subsubsection{Moisture permeability calculation}

\section{Microscopic flows}

The moisture conductance of a network element is defined by the occupying phases as well as the geometrical properties of the element. This section discusses conductances of liquid and vapour phases by which compose the conductances of an element and a conduit which is defined as a pore-to-pore hannel assembled from a throat and its two neighbouring half pores.

The liquid phase in a water-filled element flows in a laminar form because of the typically low velocity. The no-slip condition on pore walls results in Hagen-Poiseuille flow with conductance $g_{l}[\mathrm{~kg} / \mathrm{sPa}]$ :

$$
g_{l}=\frac{c_{G} \rho_{l} G A^{2}}{\mu L}
$$

with $\mu$ [Pa.s $]$ water viscosity, $L[\mathrm{~m}]$ element length, and $c_{G}\left[\mathrm{~m}^{2}\right]$ shape factor-dependent constant. The latter equals $0.5,0.5623$, and 0.6 for circular, square, and triangular cross-sections, respectively (Patzek and Kristensen 2001)

In not-fully-water-filled elements, moisture can also be transported in the liquid phase via the water film adsorbed on pore surfaces and in pore corners. The conductance of this surface water is also calculated based on Eq. 7 with a tailored flow area, and hence the shape factor $G$ and the corresponding constant $c_{G}$ are adjusted accordingly. Corner and surface adsorptions constrict the air-filled pore area in which vapour diffuses, and thus the vapour conductance should be altered accordingly.

Water vapour in a dry element is transported as a Fickian diffusion process in which vapour molecules move freely along the vapour or capillary pressure gradient. The conductance of such vapour transport in an element with constricted cross-sectional area $A^{*}$ and length $\mathrm{L}$ is formulated as follows:

$$
g_{v}=\frac{1}{1+K_{N}} \frac{\delta_{v} p_{v}}{\rho_{l} R_{v} T} \frac{A^{*}}{L}
$$

with $\delta_{v}[\mathrm{~kg} / \mathrm{msPa}]$ air's vapour permeability and $p_{v}[\mathrm{~Pa}]$ vapour pressure. The vapour molecule's Browoccur. This so-called Knudsen diffusion reduces the diffusive conductance and is represented by the 
Postprint: Islahuddin M. and Janssen H. 2019. Pore-structure-based determination of unsaturated hygric properties of porous materials. Transp Porous Med, 130:675.

Knudsen number $K_{N}[-]$ :

$$
\begin{aligned}
K_{N} & =\frac{\lambda}{2 r} \\
\lambda & =\frac{R T}{\sqrt{1+\left(M_{v} / M_{a}\right)} \pi N_{a}\left(\left(d_{v}+d_{a}\right) / 2\right)^{2} P}
\end{aligned}
$$

where $\lambda[\mathrm{m}]$ is the mean-free-path length and $N_{a}$ is the Avogadro constant. The molar masses $M$ and the collision diameters $d$ of water vapour $(v)$ and air $(a)$ are 18 and $29 \mathrm{~g} / \mathrm{mol}$, and 0.27 and $0.37 \mathrm{~nm}$, respectively.

The mixed transport of the liquid and vapour phases in an element occurs simultaneously in a parallel manner as they split the total cross-sectional area separately. Therefore, its total moisture conductance is the sum of both phase conductances calculated independently, while the total conductance of two serial elements is the inverse of their total resistances. However, assuming a continuity of the adsorbed water in two consecutive elements, its continuous-phase conductance is calculated first followed by the element-by-element superposition.

Unlike other PNMs (Hinebaugh and Bazylak 2010; Qin 2015) which ignore the flow resistance of pore bodies, the presented method considers the flow resistances of all pore bodies and throats. The moisture is therefore flowing through three different elements of a conduit: part of pore body $i$, pore throat $i j$, and part of pore body $j$. For single-phase flow, the conduit conductance $g_{i j}$ is calculated based on Eq. 10:

$$
g_{i j}=\left[\frac{1}{g_{p, i}}+\frac{1}{g_{t, i j}}+\frac{1}{g_{p, j}}\right]^{-1}
$$

with $g_{p}$ and $g_{t}$ conductance of pore body and pore throat, respectively. For multi-phase flow, these element conductances are phase-dependent and correspondingly determined by Eq. 7 or Eq. 8. In case of flow with the adsorbed water, the conduit conductance is calculated in a slightly more complex manner but still based on the electrical resistance concept. For instance, the conductance of a conduit with a dry pore body $i$, a dry pore throat $i j$, and a wet pore body $j$, as shown in Figure 2, is formulated by:

$$
g_{i j}=\left[\frac{1}{g_{v, l}}+\frac{1}{g_{p, j}}\right]^{-1}
$$

with

$$
\begin{aligned}
g_{p, j} & =g_{l, j} \\
g_{v, l} & =\left[\frac{1}{g_{v, i}}+\frac{1}{g_{v, i j}}\right]^{-1}+\left[\frac{1}{g_{l, i}}+\frac{1}{g_{l, i j}}\right]^{-1}
\end{aligned}
$$

where the subscripts $v$ and $l$ indicate the bulk vapour and bulk/surface liquid, respectively. Various moisture configurations in a conduit are solved accordingly.

\section{Macroscopic flow}

A steady-state moisture flow on the predefined moisture distribution is simulated by applying an infinitesimal capillary pressure difference over two opposing boundaries. This pressure difference acts as a transfer potential and hence provokes moisture transport in the coexisting liquid and vapour phases. The moisture flow between two neighbouring pores are driven by their capillary pressure difference. The capillary pressure at each pore body is however undetermined and has to be derived from the imposed global pressure difference. As the total mass flowing in and out of a pore body through its neighbouring pore throats is conserved, the local capillary pressure distribution is determined by solving the following set of mass balance equations:

$$
\sum g_{i j}\left(p_{c, j}-p_{c, i}\right)=0
$$

This mass balance results in a system of linear equations $A \cdot \underline{x}=\underline{b}$ in which entries $a_{i j}$, and $x_{i}$ represent the conduit conductance connecting pore body $i$ and $j$, and capillary pressure of pore body $i$, respectively. On the other hand, the right-hand-side vector $\underline{b}$ contains the effect from the boundary conditions. The resulting local capillary pressures are then used to calculate the conduit flows. 
Postprint: Islahuddin M. and Janssen H. 2019. Pore-structure-based determination of unsaturated hygric properties of porous materials. Transp Porous Med, 130:675.

https://doi.org/10.1007/s11242-019-01334-7

The total moisture flow $Q[\mathrm{~kg} / \mathrm{s}]$ through the network is calculated at a plane perpendicular to the flow direction. The corresponding network permeability $k[\mathrm{~kg} / \mathrm{msPa}]$, with the network's cross-section area $A_{n}[\mathrm{~m}]$ and length $L_{n}[\mathrm{~m}]$, is calculated from the macroscopic model of Darcy's law:

$$
Q=k \triangle p_{c} \frac{A_{n}}{L_{n}}
$$

which can be derived from the microscopic flow model using homogenisation concepts.

\section{Applications}

In this section, the presented model is applied to PNMs of two rock samples. These materials are used instead of the common building materials because the PNMs of building materials are not yet available: reconstructing the pore structure of common porous building materials, typically comprising a very wide range of pore sizes, is still problematic and is the subject of currently ongoing research. The samples used in this study are meant for exemplary purposes, to illustrate the potential of the developed model.

The unsaturated water-air system in porous media is assumed to be isothermal and subject to the standard conditions of $1 \mathrm{~atm}$ and $20^{\circ} \mathrm{C}$. Moreover, water is assumed to be a perfectly wetting fluid, which is quantified by a zero contact angle, while other fluid and condition parameters are listed in Table 2. This unique unsaturated case occurring in building materials is simulated by a code relying on a customized basic structure of OpenPNM 1.3 (Gostick et al. 2016).

Table 2: Fluid properties of water liquid and vapour.

\begin{tabular}{lccl}
\hline Property & Water & Vapour & Unit \\
\hline Viscosity & 0.001 & - & $\mathrm{Pa} . \mathrm{s}$ \\
Density & 1000 & - & $\mathrm{kg} / \mathrm{m}^{3}$ \\
Surface tension & 0.072 & - & $\mathrm{N} / \mathrm{m}$ \\
Contact angle & 0 & - & $\mathrm{rad}$ \\
Gas constant & - & 461.4 & $\mathrm{~kJ} / \mathrm{kg} \cdot \mathrm{K}$ \\
Saturation vapour pressure & - & 2339 & $\mathrm{~Pa}$ \\
Permeability & - & $1.88 \cdot 10^{-10}$ & $\mathrm{~kg} / \mathrm{msPa}$ \\
\hline
\end{tabular}

\subsection{Pore-network data}

Two PNMs, a Berea sandstone and a Carbonate (shown in Figure 1) selected from Dong and Blunt (2009), are used in this study. They are used with original and with downscaled dimensions, extending the studied pore sizes down to the nanometer range. The downscaled networks are developed by scaling down the original networks a thousand times, transforming their micrometer range into a nanometer range.

The two PNMs are chosen based on their distinct properties that are expected to generate varying storage and transport properties. Moreover, the impacts of certain topological and geometrical features, as listed in Table 3, on the calculated hygric properties can be analysed. In general, the Carbonate has a slightly smaller porosity than the Berea, with higher closed porosity. While the closed porosity is isolated from the network sides, the open porosity is governed by the continuously connected elements (spanning clusters) linking the inlet to outlet sides, and the surface clusters connected only to inlet or outlet. Such cluster types define the topology variations of the two networks, which can visually be identified in Figure 1. The topology variation is quantitatively represented by an average coordination number illustrating the average number of pore throats attached to a pore body. 
Postprint: Islahuddin M. and Janssen H. 2019. Pore-structure-based determination of unsaturated hygric properties of porous materials. Transp Porous Med, 130:675.

https://doi.org/10.1007/s11242-019-01334-7

Table 3: The network properties of Berea sandstone and Carbonate network models after deleting the isolated elements which are not connected to neither inlet nor outlet side.

\begin{tabular}{|c|c|c|c|}
\hline Property & & Berea Sandstone & Carbonate \\
\hline \multirow{2}{*}{$\begin{array}{l}\text { Sample size }[\mathrm{mm}] \\
\text { Porosity [-] }\end{array}$} & \multirow[t]{2}{*}{$\triangle \mathrm{x}, \triangle \mathrm{y}, \triangle \mathrm{z}$} & 2.138 & 2.138 \\
\hline & & 0.195 & 0.148 \\
\hline \multirow{6}{*}{ Number of [-] } & Pores & 6370 & 5290 \\
\hline & Throats & 12417 & 8719 \\
\hline & Clusters & 17 & 121 \\
\hline & Spanning pores & 6333 & 4493 \\
\hline & Surface pores & 37 & 797 \\
\hline & Isolated pores & 275 & 3618 \\
\hline \multirow[t]{3}{*}{ Pore radius $[\mu \mathrm{m}]$} & Average & 15.54 & 13.54 \\
\hline & Minimum & 0.55 & 0.54 \\
\hline & Maximum & 70.25 & 111.18 \\
\hline \multirow[t]{3}{*}{ Throat radius $[\mu \mathrm{m}]$} & Average & 7.17 & 6.47 \\
\hline & Minimum & 0.54 & 0.54 \\
\hline & Maximum & 56.61 & 108.01 \\
\hline \multirow[t]{3}{*}{ Pore length $[\mu \mathrm{m}]$} & Average & 48.22 & 43.45 \\
\hline & Minimum & 0.04 & 0.04 \\
\hline & Maximum & 339.02 & 590.51 \\
\hline \multirow[t]{3}{*}{ Throat length $[\mu \mathrm{m}]$} & Average & 22.74 & 17.54 \\
\hline & Minimum & 0.08 & 0.02 \\
\hline & Maximum & 109.06 & 127.55 \\
\hline \multirow{3}{*}{ Pore shape factor [-] } & Average & 0.0276 & 0.0281 \\
\hline & Minimum & 0.0102 & 0.0084 \\
\hline & Maximum & 0.0625 & 0.0591 \\
\hline \multirow[t]{3}{*}{ Throat shape factor [-] } & Average & 0.0313 & 0.0312 \\
\hline & Minimum & 0.0100 & 0.0084 \\
\hline & Maximum & 0.0625 & 0.0625 \\
\hline \multirow[t]{3}{*}{ Number of shapes [-] } & Circular & 0 & 0 \\
\hline & Square & 72 & 65 \\
\hline & Triangular & 18715 & 13944 \\
\hline Coordination number [-] & Average & 3.90 & 3.30 \\
\hline
\end{tabular}

The radius of variously shaped pore bodies and throats describes the size of the inscribed maximal ball. Figure 4 shows the pore body and throat radius distributions of both PNMs and indicates that

those networks are single scale, only spanning a limited range of radii. 
Postprint: Islahuddin M. and Janssen H. 2019. Pore-structure-based determination of unsaturated hygric properties of porous materials. Transp Porous Med, 130:675.

(a)

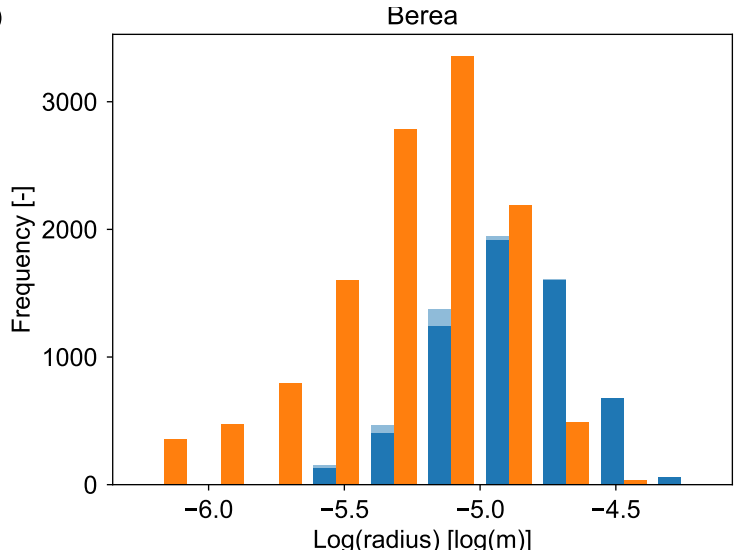

(c)

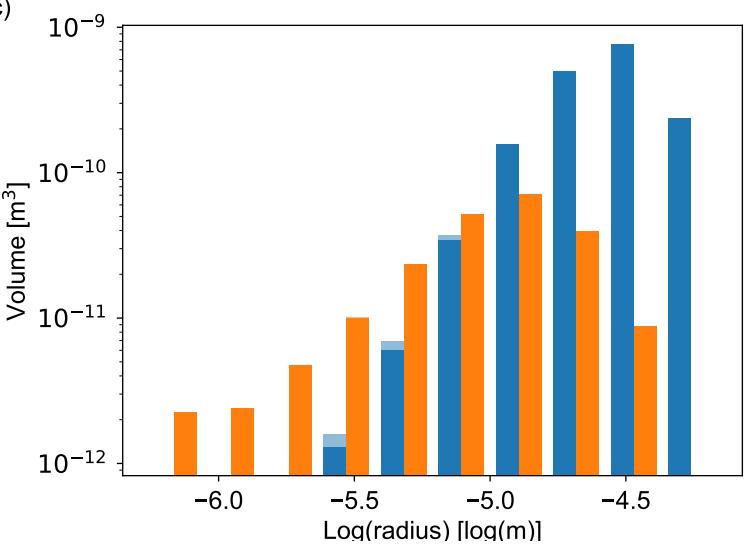

(b)
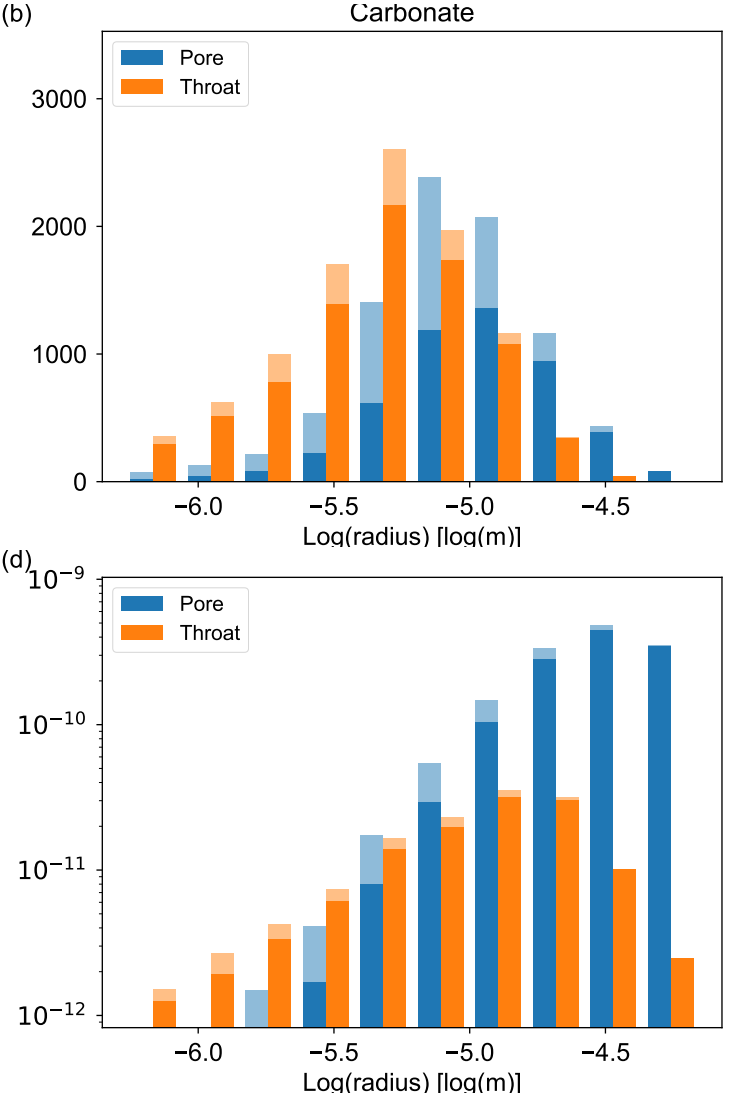

Figure 4: Pore and throat radius distributions of Berea (left) and Carbonate (right) networks. The fractions of the histograms with transparent colours represent the trimmed/isolated elements.

\section{$3.2 \quad$ Hygric properties}

The resulting moisture retention and permeability curves of the original and downscaled PNMs are discussed in this section. The contributions of capillary condensation, corner and surface adsorptions to the storage property, as well as their corresponding flows to the transport property, are analysed. Moreover, the investigation also considers the hysteresis effect of the ad-desorption cycle, and the air entrapment in an imbibition process.

\subsubsection{Capillary condensation, corner and surface adsorptions}

Adsorption moisture retention and permeability curves of the original and the downscaled PNM's of Berea and Carbonate are shown in Figure 5. In general, as capillary pressure increases, moisture content also increases with the occurrence of a single steep rise until the saturated value is reached. This steep increment is because of the capillary condensation gradually occurring from the smallest to the biggest pore elements, and further confirms the narrowness of the pore size distributions shown in Figure 4. The condensed water provides much higher conductance for moisture to flow in liquid form (as suggested by Eq. 7), and hence induces a steep permeability climb.

Additionally, the corner adsorption increases the moisture retention prior to the condensation mechanism, as shown by the orange curves in Figure 5. And similarly, the corner flows also raise the transport property before the bulk liquid flow occurs. This permeability increment applies to the original and the downscaled networks, which shows the significance of the corner water transport in pore networks at intermediate saturations. Moreover, contrary to the cases without corner adsorption in which the corresponding permeability curves climb suddenly and significantly, the permeability curves are smoother, i.e. the increment occurs gradually and linearly. This significant effect may be caused mainly by the connected corner and surface water of two neighbouring elements, which results in a spanning water film by which moisture flows from inlet to outlet in liquid phase. As capillary pressure increases, this spanning corner water is swelling towards the pore centre and gradually produces higher permeability. The network permeability hence increases moderately, instead of the previous permeability jump. 
Postprint: Islahuddin M. and Janssen H. 2019. Pore-structure-based determination of unsaturated hygric properties of porous materials. Transp Porous Med, 130:675.

https://doi.org/10.1007/s11242-019-01334-7
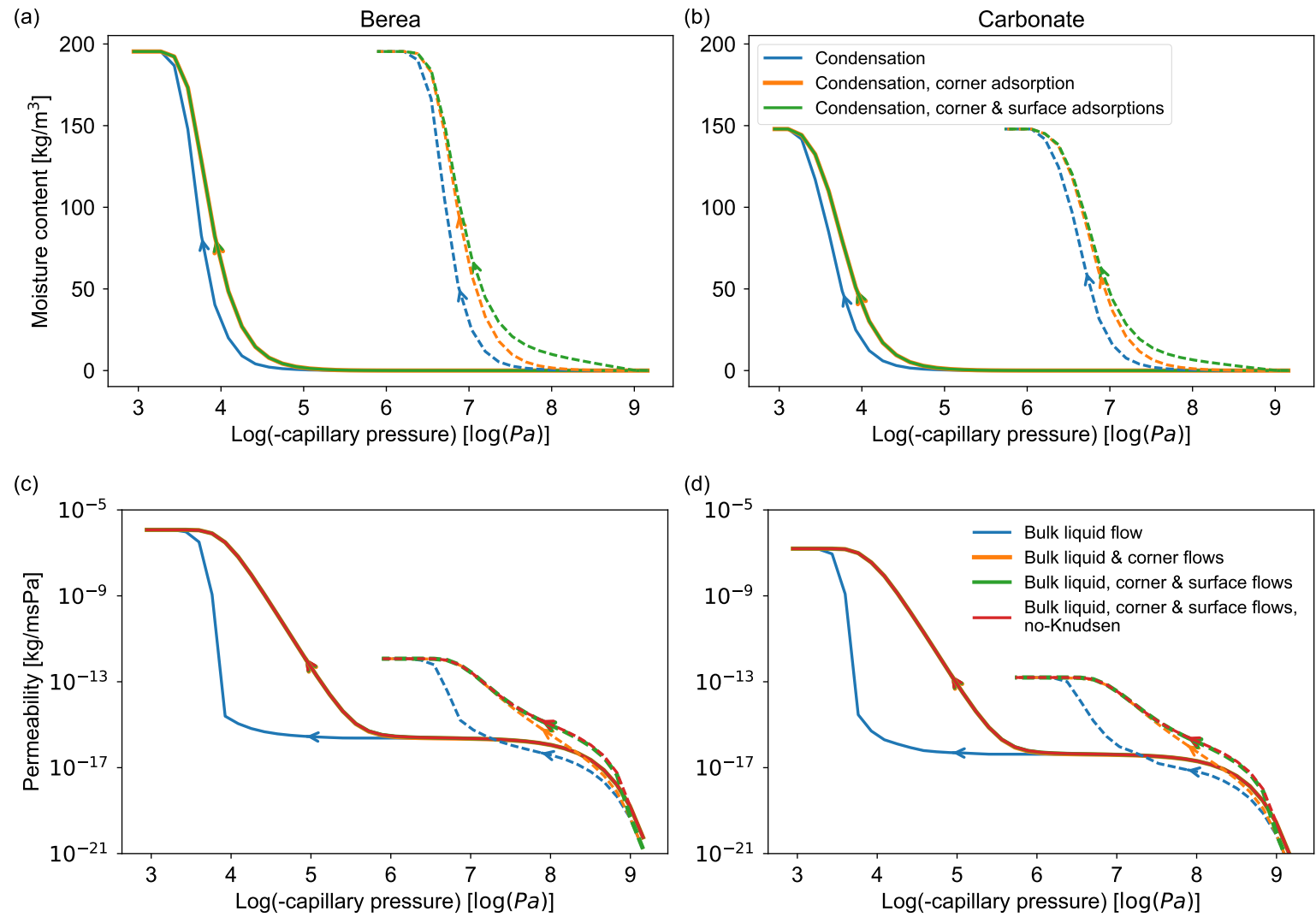

Figure 5: Adsorption moisture retention (top) and permeability (bottom) curves of the Berea (left) and Carbonate (right) pore-networks of several cases: 1) capillary condensation, 2) capillary condensation and corner adsorption 3) capillary condensation, corner and surface adsorptions. The continuous and the dashed curves represent the original and the downscaled networks, respectively.

At low capillary pressures, the corner and surface water films do not significantly contribute to the storage of the original networks, as shown by the orange and green curves in Figure 5. This negligible moisture content stems from the course-only pore structures, which results in minimal surface area to hold corner and surface films. In contrast, the corresponding permeability curves increase between $-10^{9}$ and $-10^{8} \mathrm{~Pa}$ owing to the rise of vapour pressure, as suggested by the vapour conductance in Eq. 8, since moisture is mainly diffused in vapour phase. For the downscaled networks (the dashed curves), however, the surface adsorption leads to higher moisture content at low capillary pressures as the nano pores, which provide much larger surface area, hold a significant amount of moisture in the form of adsorbed surface water. The corresponding surface flow similarly contributes to transport by increasing the permeability. It can then be concluded that only in fine structures the surface adsorption and flow are essential to storage and transport.

Parallel to the surface flow, vapour molecules, while diffusing, may often collide with pore walls/surface films if the pore sizes are comparable or smaller than the molecule's mean-free-path length. These collisions to pore walls reduce the vapour diffusion, as suggested by a large Knudsen number in Eq. 9, and thus decrease the network permeability. Although this Knudsen diffusion has been numerically shown to be crucial only in fine networks (Islahuddin and Janssen 2016), the analysis did not include the corner and surface flows, which are here shown to be important. However, exclusion of Knudsen does not strongly impact the permeability curves of the downscaled networks, as shown in Figure 5, and the differences are limited to the very small capillary pressures around $-10^{9} \mathrm{~Pa}$. This hence confirms that the Knudsen

\subsubsection{Hysteresis}

The desorption moisture retention curves deviate from the adsorption cases for both networks, as shown in Figure 6 (a) and (b). These deviations are due to the desorption accessibility condition, wherein the draining pore must be connected with an air path to the ambient atmosphere, which results in a spatially 
Postprint: Islahuddin M. and Janssen H. 2019. Pore-structure-based determination of unsaturated hygric properties of porous materials. Transp Porous Med, 130:675.
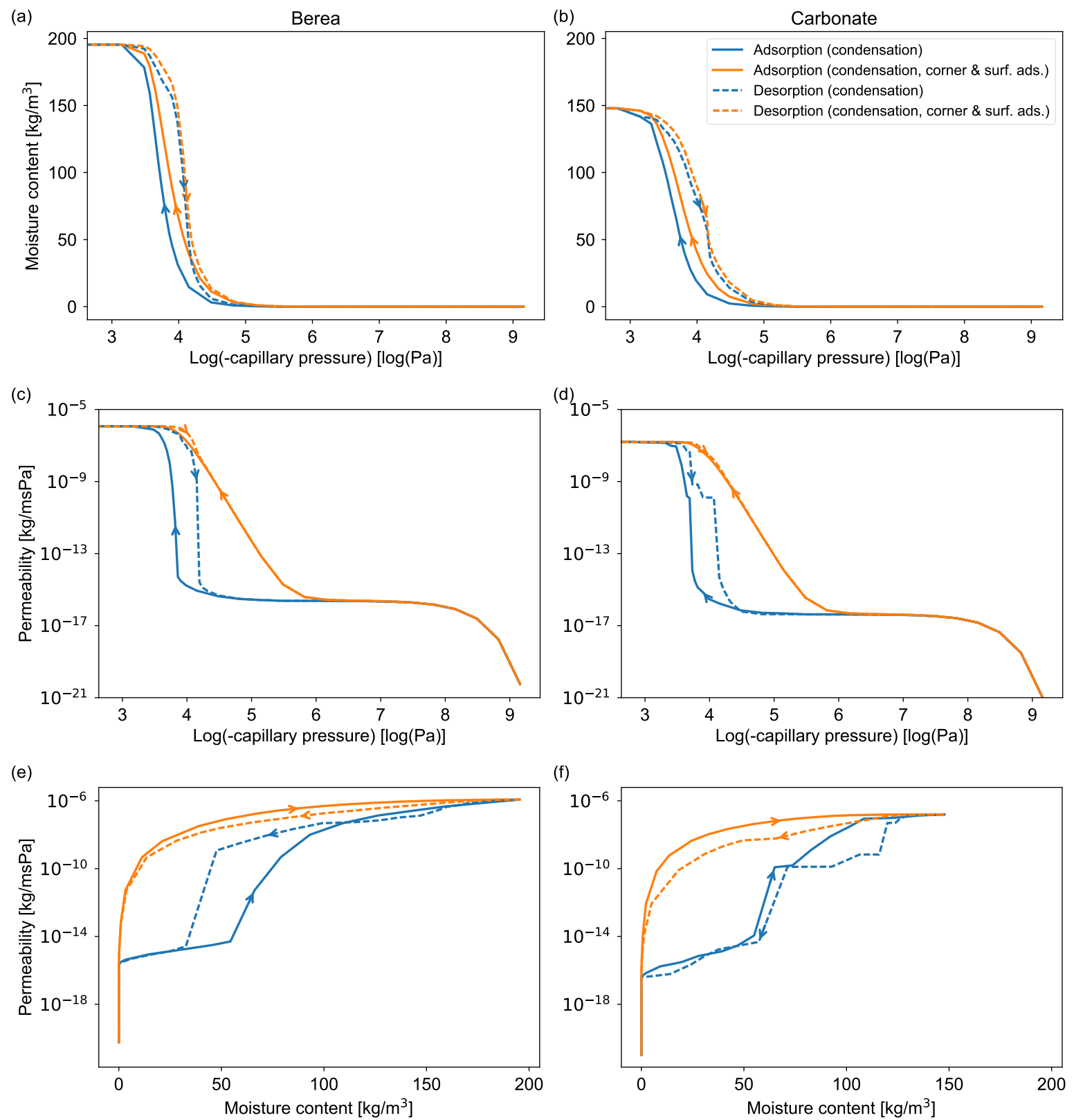

Figure 6: Adsorption - desorption curves of Berea sandstone (left) and Carbonate (right).

gradual desorption from the outlet pores to the internal pores. Moreover, neighbouring pore throats are commonly smaller than the corresponding pore bodies, hence delaying the evaporation of the biggest fraction of moisture in the pore structure. Therefore, in addition to how big the pore size is, the spatial position relative to the bulk air and connectivity to other network elements determine the deviation of desorption from the adsorption process. Such variation is illustrated in Figure 7 by the spatial moisture distribution in the considered PNMs. 
(a)

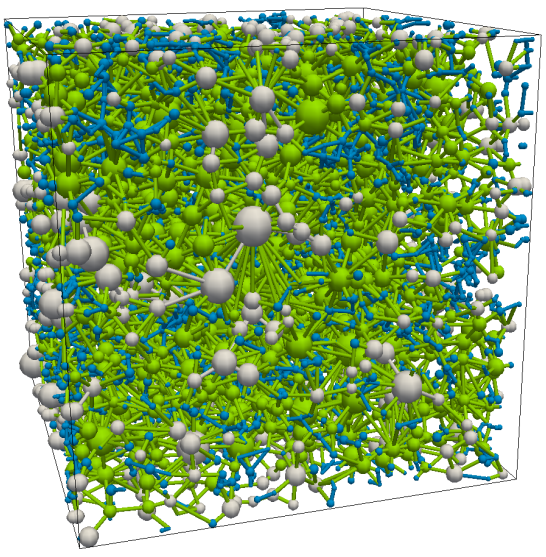

(b)

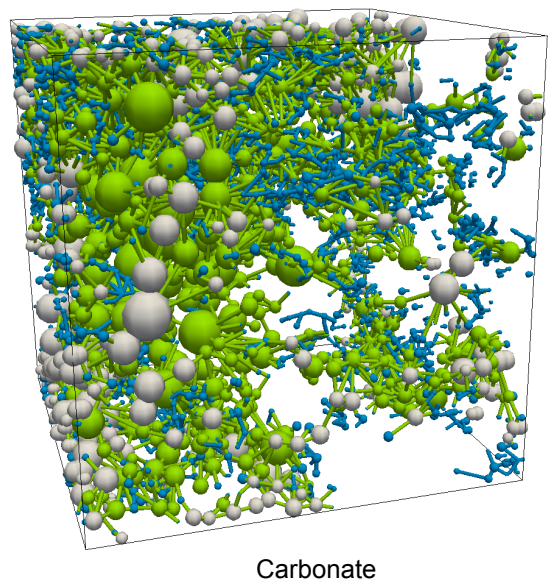

Figure 7: The spatial moisture distributions in three-dimensional PNMs of (a) Berea and (b) Carbonate illustrating the hysteresis at $-8431 \mathrm{~Pa}$ (or 3.92 in log scale). The network elements are coloured based on the phase occupation: white and blue represent water vapour and water liquid, respectively, while green represents both desorption water liquid and adsorption water vapour. These green-coloured elements correspond to the moisture difference between the ad- and desorption curves shown in Figure 6.

With regard to Figure 6 (a) - (d), initially saturated networks remain saturated until the liquid water of the biggest pore at the open boundary evaporates. This first evaporation occurs at the so-called entry capillary pressure, which is most probably smaller than that of the last condensation. In this nearsaturation region, the permeability reduction is minimal since evaporation is sporadic and limited to the pore center because of corner and surface water. While adsorbed water films are vaporised, evaporation continues subsequently in other smaller elements that are in contact with the air-water front reaching the internal part of the network. The invasion is suspended at certain capillary pressures due to the blocking by small wet throats as widely known as the ink-bottle effect. As the capillary pressure decreases, these small throats are invaded, as well as all other connected bigger elements that have been locked by these ink-bottle phenomena. However, the permeability drops moderately as the dominant spanning liquid clusters are maintained by the adsorbed water at surfaces and in corners.

In contrast to our results in Islahuddin and Janssen (2016), where ad- and desorption permeabilities differed considerably, Figure 6(c) and (d) show that corner and surface flows almost eliminate the permeability hysteresis. The only apparent hysteresis is at the beginning of desorption, attributed to the entry capillary pressure. This hysteresis is less visible in the Carbonate networks since their biggest pores are located at the boundary sides. Apart from that, corner and surface films completely remove the primary permeability jump in both adsorption and desorption curves by maintaining the existence of the global connectivity of the liquid clusters. These water films also reduce the secondary permeability jump, attributed to the local mechanisms of spontaneous condensation and evaporation of the whole per a pore, by their gradual swelling/shrinking. Those local and global liquid formations and destructions determine the shape of the permeability curves, and thus define the permeability hysteresis.

Figure 6(e) and (f) show the permeabilities of ad- and desorption with respect to moisture contents. The ad- and desorption permeabilities generally coincide at low and saturated moisture contents, and disagree in intermediate range. The discrepancy, however, is minimized by the corner and surface adsorptions and flows. This deviation indicates that, microscopically, for the same moisture content, the network permeabilities may not be unique.

\subsubsection{Air Entrapment}

The water front invasion in an imbibition simulation imposes a delay in the moisture storage increase until the entry capillary pressure, from where on the moisture storage drastically increases. As shown in Figure 8, the resulting sharp turn of the dashed blue moisture retention and permeability curves along a narrow capillary range distinguishes the imbibition storage and transport properties from that of adsorption. Consequently, further rapid front-water movement invades all network elements that are connected to the inlet site. Disregarding air entrapment and corner and surface adsorptions (the dashed blue curves), the maximum storage indicates that the Carbonate network is less connected than the Berea network. And since most building materials are well-connected networks, the Berea network is 
Postprint: Islahuddin M. and Janssen H. 2019. Pore-structure-based determination of unsaturated hygric properties of porous materials. Transp Porous Med, 130:675.

quite representative of building materials.

(a)

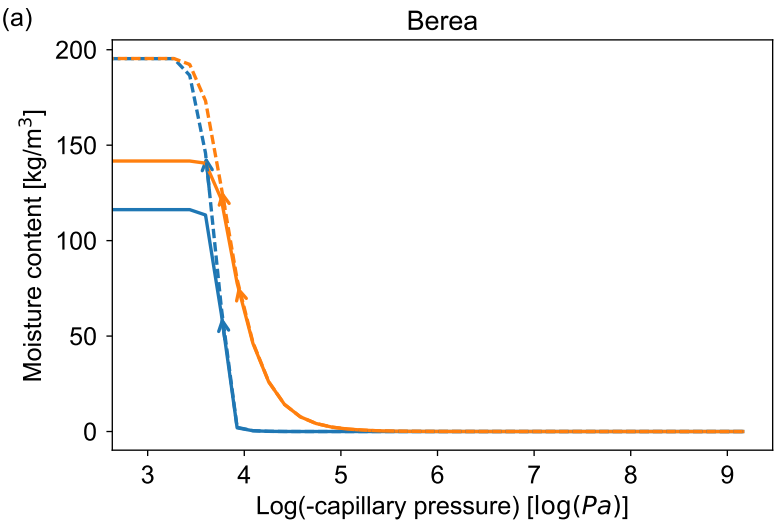

(c)

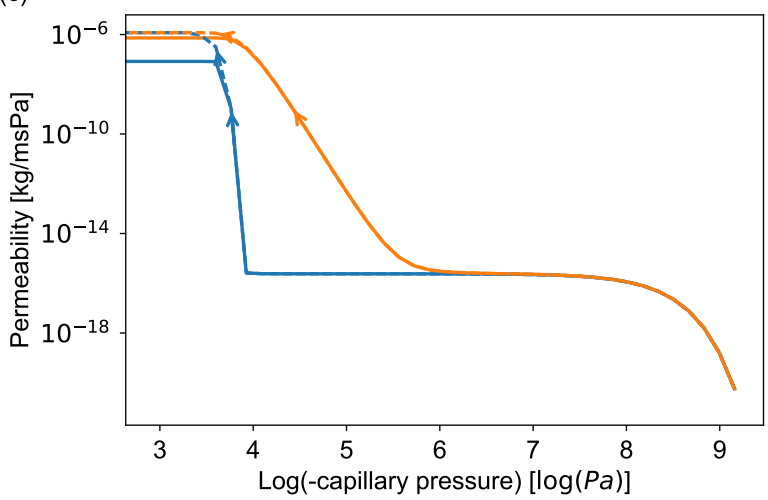

(b)

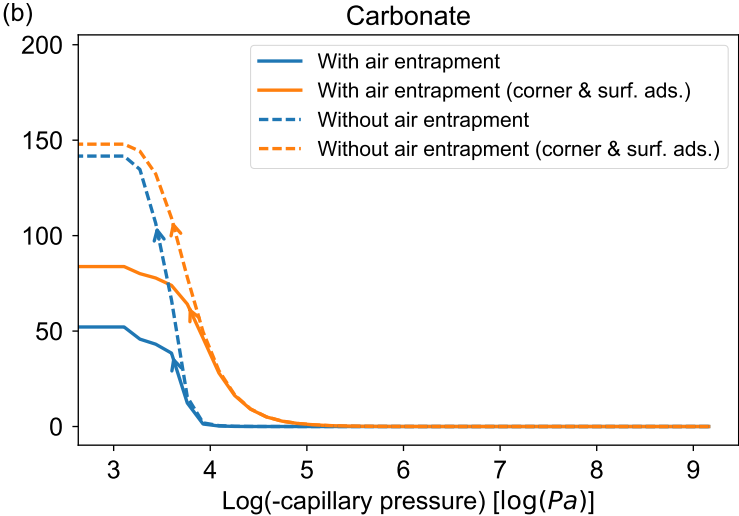

(d)

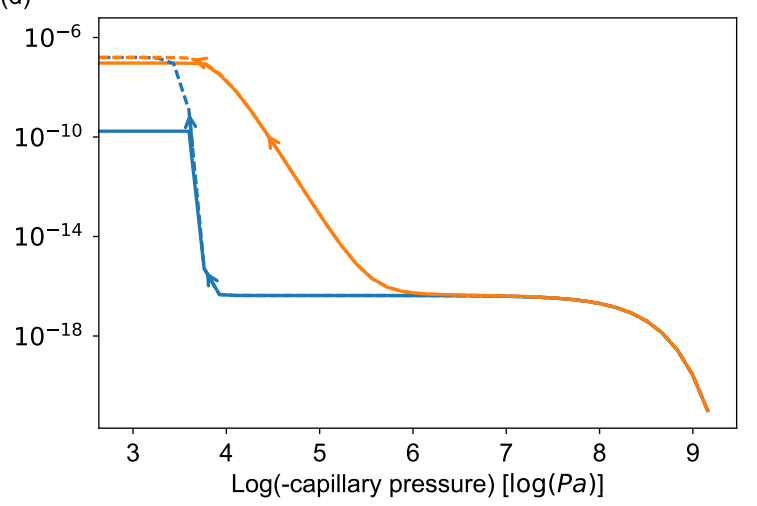

Figure 8: Imbibition moisture retention and permeability curves of the Berea sandstone (left) and Carbonate (right) networks.

(a)

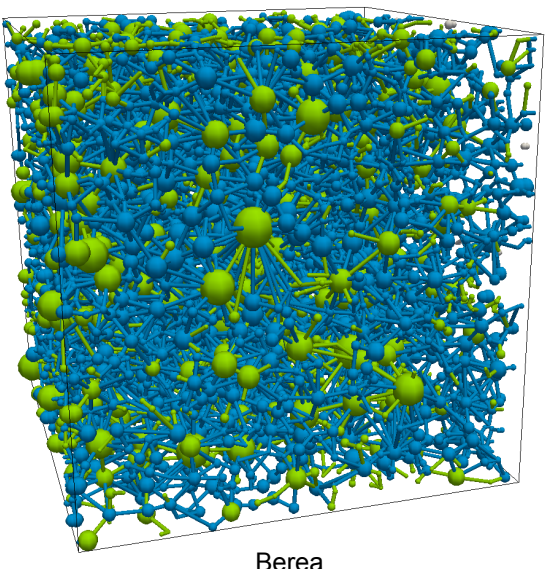

(b)

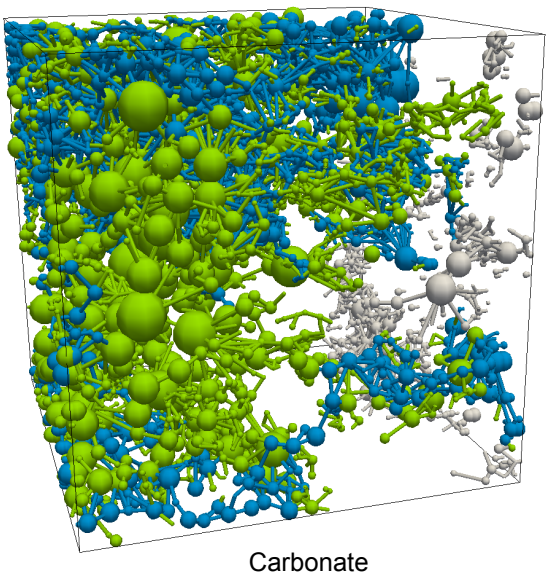

Figure 9: The spatial moisture distributions in three-dimensional PNMs of (a) Berea and (b) Carbonate illustrating the imbibition at $-13 \mathrm{~Pa}$. The elements are divided into invaded wet elements (blue), isolated dry elements (white), and entrapped dry elements (green). These green-coloured elements correspond to the moisture difference between the dashed and continuous blue curves shown in Figure 8.

The integration of air entrapment into the imbibition simulation leads to air remaining inside a pore because the air is surrounded by pore water in already invaded smaller elements. As a result, the maximum storage drops to the so-called capillary moisture content as shown by the continuous blue curves in Figure 8. The capillary moisture content is highly influenced by the pore connectivity where less connected pore spaces result in higher storage drop, as can be visually examined in Figure 
Postprint: Islahuddin M. and Janssen H. 2019. Pore-structure-based determination of unsaturated hygric properties of porous materials. Transp Porous Med, 130:675.

https://doi.org/10.1007/s11242-019-01334-7

9. The majority of the entrapped air (shown in green) belongs to the dead-end parts of the spanning clusters. In well-connected networks, pore air still has many alternative ways to flow out when some of its neighbours has already been blocked by the pore water. Similar to the maximum-storage drop, the maximum permeabilities are also reduced. However, the permeability reductions may be more moderate since the trapping mechanism may only cut the liquid connectivity in a few channels while preserving a large part of the spanning liquid clusters.

The incorporation of corner and surface adsorptions (the dashed orange curves) smoothens the moisture retention and permeability curves with earlier increments. The corner and surface adsorptions also define the maximum storage in imbibition processes. The limitation of connectivity to the water front is boosted by the formation of adsorbed water on pore wall and corners, which thus reaches all network elements ignoring the connectivity condition. This role can be observed from the maxima of the Carbonate's imbibition retention curves in which the case with corner and surface adsorption (the dashed orange curve) marks higher maximum storage than that of without the corner and surface adsorptions (the dashed blue curve). In contrast, the corresponding permeability curves reach the same maximum value, since the moisture flow is only determined by the backbone of the spanning cluster, and the clusters that are not connected to the inlet do not belong to the backbone cluster.

\section{Validation}

In the section above, the capabilities of the hygric property model have been illustrated, based on two networks for rock materials. To validate that model, its numerical simulations are compared to experimental results for a ROBU P100 sintered-glass filter. This material has been preferred over an actual building material, given that it only has coarse pores ranging from 2 to $200 \mu \mathrm{m}$, hence allowing a reliable characterization of its pore structure via X-ray CT (Van De Walle et al. 2018). To transform the obtained pore structure to a PNM, both the original maximal-ball (MB) network extraction (Dong and Blunt 2009) and its recently revised version (https://github.com/aliraeini/pnextract, accessed May $15,2018)$ are used, illustrating the variability due to the network extraction. The new extraction has been adjusted in the pore-throat definition and in the calibration to single-phase flow simulations in sandstone rocks. Relative to the old code, the new code yields fewer pore elements as shown by the pore size distributions in Figure 10. Since the related throat volumes are significantly higher, it appears that the new code tends to lump small elements together into throats. The new code moreover produces more regular triangular pores while the old code gives more slit-shaped triangles. The measurements performed on the glass filter include mercury intrusion porosimetry (MIP) to determine the desorption moisture retention curve, free water uptake testing to obtain the capillary moisture content and the moisture diffusivity, hanging-water-column experiments to find the near-saturation moisture permeabilities and cup vapour transmission measurements to determine the vapour permeabilities. These measurements unfortunately do not cover the full range of applicability of the hygric property model, but the current limitations on hygric property determination impede a complete validation.

(a)

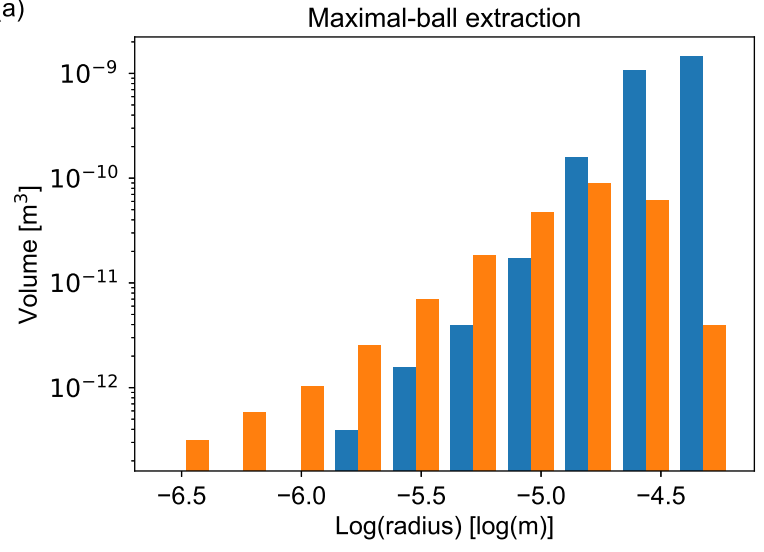

(b)

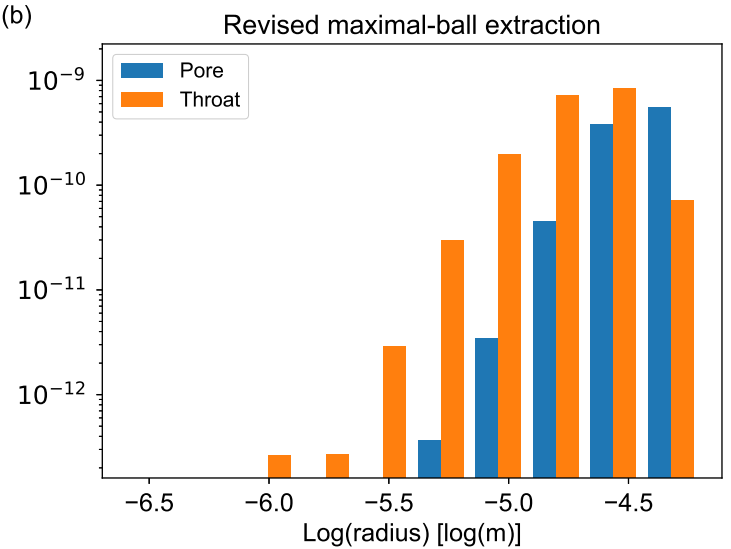

Figure 10: Pore volume distribution of the glass filter networks resulted by the original (left) and revised (right) maximal-ball network extraction codes, respectively. 
Postprint: Islahuddin M. and Janssen H. 2019. Pore-structure-based determination of unsaturated hygric properties of porous materials. Transp Porous Med, 130:675.

https://doi.org/10.1007/s11242-019-01334-7

\subsection{Moisture storage}

Figure 11(a) depicts the measured and simulated desorption moisture retention curves for the glass filter.

The variability in the experimental data may originate from differences in sample sizes, in measuring procedure and/or equilibrium criterion (Roels et al. 2004b, 2003a). As mercury is not spontaneously adsorbed onto pore walls or into pore corners, the simulation excludes corner and surface adsorption. In general, the simulations and measurements agree well, certainly for the new extraction code. The differences between the two codes reflect the differences in the pore radii distributions, see Figure 10. The small difference of the saturated moisture content originates from the deviating handling of boundary pores: the bigger pore volume of the new code results in a higher volume adjustment. Figure 11(b) compares the measured and simulated capillary moisture content, plus the entire adsorption moisture retention curve from the simulation. In this simulation, an imbibition process with air entrapment is calculated. For both extraction codes, the simulated capillary moisture contents are at the high end of the measured results. One should keep in mind though that the capillary absorption in this rough-porous material is probably hindered by gravity (Fries and Dreyer 2008). From the shown measured results, the highest two values stem from short samples $(3 \mathrm{~cm}$ high), which are least affected by gravity. In relation to these values, the overestimation by the simulations is only $3 \%$ or $7 \%$ for the old and new code respectively, which is far below the difference typically found in interlaboratory evaluations (Roels et al. 2003a).

\subsection{Moisture transport}

Figures 11(c-d) compare measured and simulated permeabilities: Figure 11(c) presents moisture permeabilities in the high-saturation range, Figure 11(d) shows vapour permeabilities in the low-saturation range. The old extraction code typically gives overestimations with a factor 2 to 2.5. The new code on the other hand yields a very good agreement between experiments and simulations. This new code has been calibrated externally for single-phase flow simulations in sandstone rocks, and the flow regimes in these high- and low-saturation ranges resemble single-phase flow quite much. Figures 11(e-f) finally compare measured and simulated diffusivities. The measured diffusivities are derived from X-ray-visualised moisture content profiles during a free water uptake test (Carmeliet et al. 2004). The simulated diffusivities are obtained from the moisture retention and permeability curves, calculated with the imbibition invasion algorithm. These diffusivities are determined based on the Eq. 11:

$$
D=\frac{k}{d w / d p_{c}}
$$

with $D\left[\mathrm{~m}^{2} / \mathrm{s}\right]$ the diffusivity, $\mathrm{k}[\mathrm{kg} / \mathrm{msPa}]$ the moisture permeability, and $\mathrm{dw} / \mathrm{dpc}\left[\mathrm{kg} / \mathrm{m}^{3} \mathrm{~Pa}\right]$ the moisture capacity, being the derivative of the moisture retention curve. Figure 11(e) depicts the diffusivities in function of moisture content, Figure 11(f) uses the ratio of the moisture content over the capillary moisture content. The latter presentation aims at correcting for the difference in the measured and simulated capillary moisture contents: $270 \mathrm{~kg} / \mathrm{m}^{3}$ in the measurement, due to the use of a high sample, versus $318 \mathrm{~kg} / \mathrm{m}^{3}$ and $332 \mathrm{~kg} / \mathrm{m}^{3}$ in the simulation. As before, there is a good agreement for the new extraction, while the old extraction leads to an overestimation. At very low moisture contents the simulated diffusivities show the typical 'dip' (Pel et al. 1996), which experimentally cannot be obtained by free water uptake tests however; instead drying experiments are required. In the proposed hygric property model, this typical profile is a direct result from the simulation of unsaturated moisture storage and transport at all moisture contents. At the higher moisture contents, the deviations between the measured and simulated diffusivities are somewhat higher, which is probably highly related to the deviations between the measured and simulated capillary moisture content, see above. 
Postprint: Islahuddin M. and Janssen H. 2019. Pore-structure-based determination of unsaturated hygric properties of porous materials. Transp Porous Med, 130:675.

(a)

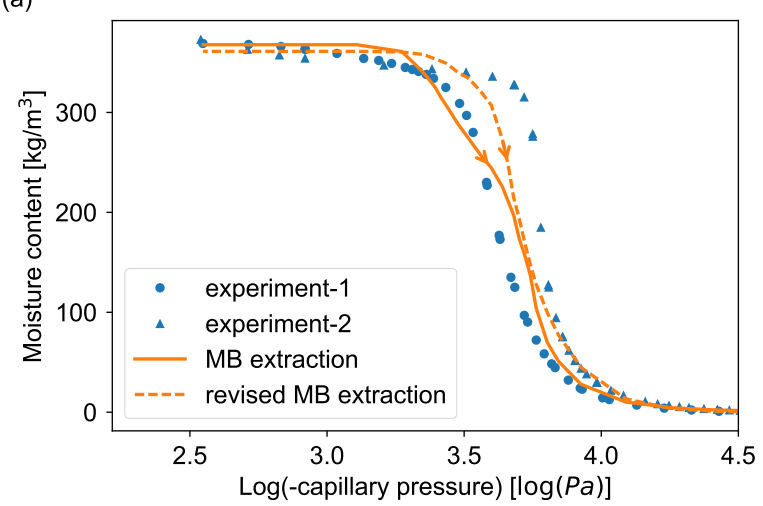

(c)

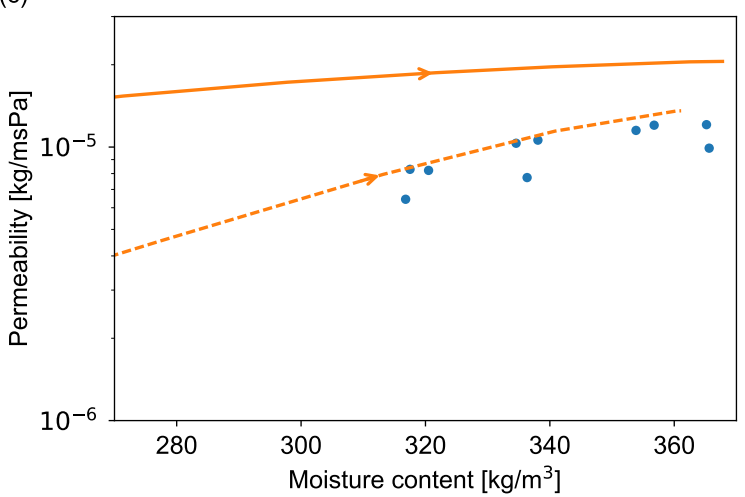

(e)

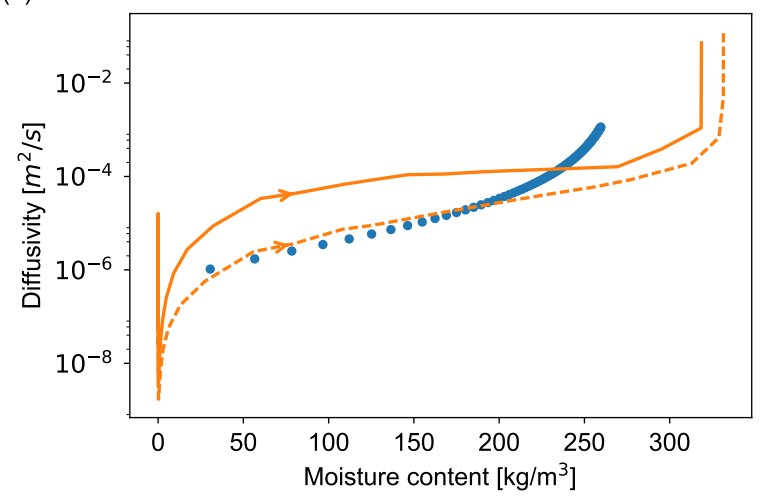

(b)

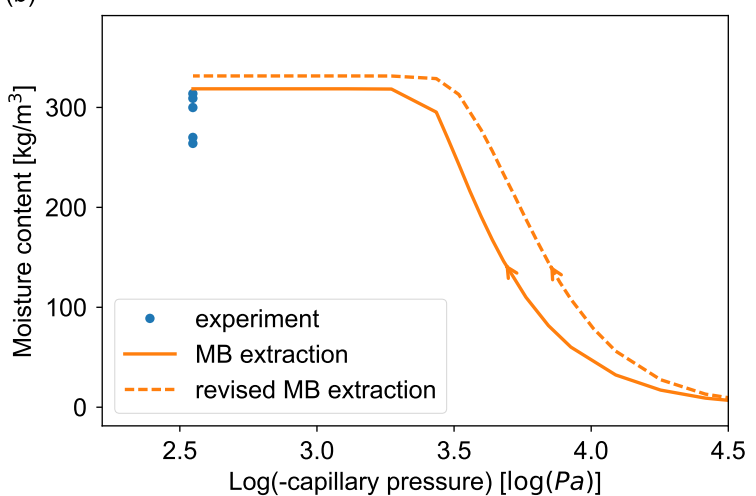

(d)

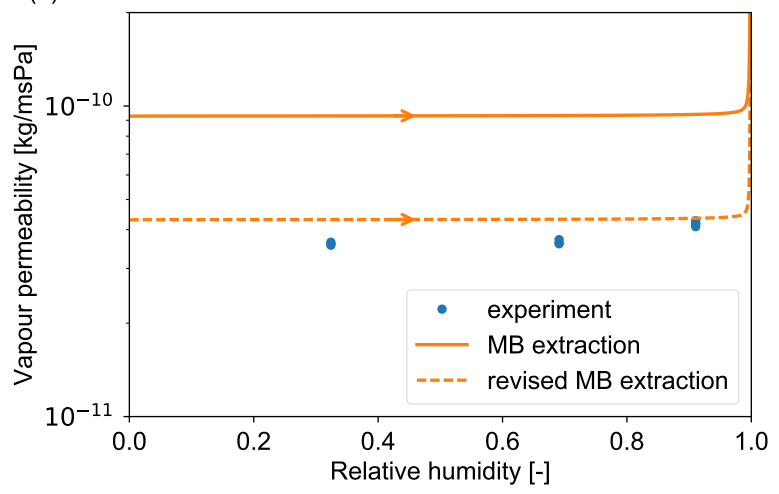

(f)

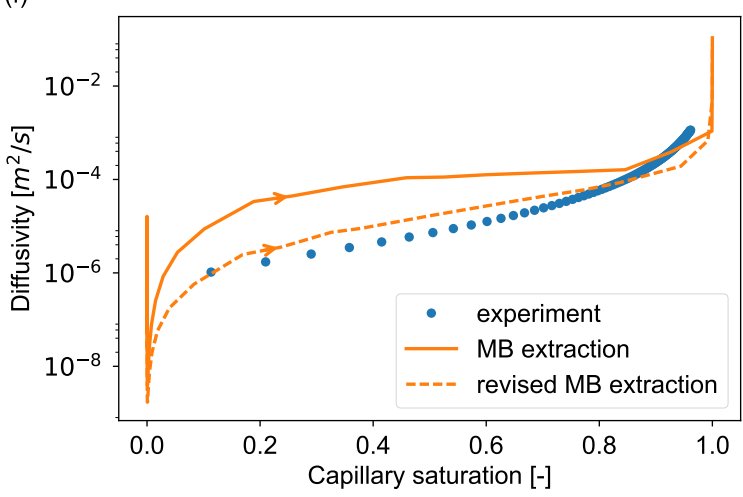

Figure 11: Measured (dot) and simulated (line curves) properties of the sintered glass:

(a) MIP data and moisture retention curves of desorption

(b) Capillary absorption data and moisture retention curves of imbibition with air entrapment

(c) Permeability - moisture content data and curves of adsorption in the over capillary - saturated region.

(d) Vapour permeability - relative humidity data and curves of adsorptions

(e-f) Diffusivity data and curves of imbibition with air entrapment with respect to: (e) the moisture content, (f) the capillary saturation.

\subsection{Discussion}

Given the fine agreement between the measured and simulated (based on the new code) moisture storage and transport properties, the validation of the hygric property model for the glass filter can be considered successful. Such successful validation supports the potential of pore-structure-based determination of the unsaturated hygric properties of porous materials. It should be noted though that the glass filter is a coarse-porous material, and that the model still is to be validated for actual building materials, with typically also fine-porous porosity present. Efforts are at present under way to provide the necessary pore structure and hygric property data. Once these become available, we will further evaluate the deviations between the two extraction methods. 
Postprint: Islahuddin M. and Janssen H. 2019. Pore-structure-based determination of unsaturated hygric properties of porous materials. Transp Porous Med, 130:675.

https://doi.org/10.1007/s11242-019-01334-7

\section{Conclusions}

A numerical approach to determine unsaturated moisture storage and transport properties of porous (building) materials directly from their pore structure has been presented and validated in this paper. The presented method simulates quasi-static moisture invasion and unsaturated moisture flow on PNMs. Our conclusions can therefore be summarised as follows:

1. The presented pore-scale model has great potential to accurately determine the moisture storage and transport properties simultaneously.

2. The capillary condensation and the related bulk liquid flow are the main storage and transport processes, respectively.

3. Corner adsorption and flow do however contribute quite significantly to the storage and transport properties at the intermediate capillary pressures.

4. Surface adsorption and flow are crucial only in nanopores. Additionally, Knudsen diffusion is also only important in nanopores.

5. The determination model is well validated for coarse pore systems.

\section{Acknowledgements}

The authors gratefully thank Professor Jeff Gostick for making his code open source, and Dr. Steven

Claes and Dr. Chi Feng for their PNMs and measured data of the sintered-glass filter, respectively. Muhammad Islahuddin thanks Dr. Evy Vereecken for fruitful discussions.

\section{References}

Badmann R, Stockhausen N, Setzer MJ (1981) The statistical thickness and the chemical potential of adsorbed water films. J Colloid Interface Sci 82(2):534-542, DOI 10.1016/0021-9797(81)90395-7

Bakke S, Øren PE (1997) 3-D Pore-Scale Modelling of Sandstones and Flow Simulations in the Pore Networks. SPE J 2(02):136-149, DOI 10.2118/35479-PA

Baldwin CA, Sederman AJ, Mantle MD, Alexander P, Gladden LF (1996) Determination and Characterization of the Structure of a Pore Space from 3D Volume Images. J Colloid Interface Sci 181(1):79-92, DOI 10.1006/jcis.1996.0358

Carmeliet J, Roels S (2001) Determination of the Isothermal Moisture Transport Properties of Porous Building Materials. J Build Phys 24(3):183-210, DOI 10.1106/Y6T2-9LLP-04Y5-AN6T

Carmeliet J, Roels S (2002) Determination of the Moisture Capacity of Porous Building Materials. J Therm Envel Build Sci 25(3):209-237, DOI 10.1106/109719602022835

Carmeliet J, Descamps F, Houvenaghel G (1999) A Multiscale Network Model for Simulating Moisture Transfer Properties of Porous Media. Transp Porous Media 35(1):67-88, DOI 10.1023/A: 1006500716417

Carmeliet J, Hens H, Roels S, Adan O, Brocken H, Cerny R, Pavlik Z, Hall C, Kumaran K, Pel L (2004) Determination of the Liquid Water Diffusivity from Transient Moisture Transfer Experiments. J Build Phys 27(4):277-305, DOI 10.1177/1097196304042324

Chatzis I, Dullien F (1977) Modelling Pore Structure By 2-D And 3-D Networks With ApplicationTo Sandstones. J Can Pet Technol 16(01):97-108, DOI 10.2118/77-01-09

Descamps F (1997) Continuum and discrete modelling of isothermal water and air flow in porous media. PhD thesis, KU Leuven, Belgium, DOI 10.13140/2.1.1158.5601

Dong H, Blunt MJ (2009) Pore-network extraction from micro-computerized-tomography images. Phys Rev E 80(3):036307, DOI 10.1103/PhysRevE.80.036307 
Postprint: Islahuddin M. and Janssen H. 2019. Pore-structure-based determination of unsaturated hygric properties of porous materials. Transp Porous Med, 130:675.

https://doi.org/10.1007/s11242-019-01334-7

Feng C, Janssen H, Feng Y, Meng Q (2015) Hygric properties of porous building materials: Analysis of measurement repeatability and reproducibility. Build Environ 85:160-172, DOI 10.1016/j.buildenv. 2014.11.036

Fries N, Dreyer M (2008) An analytic solution of capillary rise restrained by gravity. J Colloid Interface Sci 320(1):259-263, DOI 10.1016/j.jcis.2008.01.009

Gostick J, Aghighi M, Hinebaugh J, Tranter T, Hoeh MA, Day H, Spellacy B, Sharqawy MH, Bazylak A, Burns A, Lehnert W, Putz A (2016) OpenPNM: A Pore Network Modeling Package. Comput Sci Eng 18(4):60-74, DOI 10.1109/MCSE.2016.49

Gostick JT, Ioannidis MA, Fowler MW, Pritzker MD (2007) Pore network modeling of fibrous gas diffusion layers for polymer electrolyte membrane fuel cells. J Power Sources 173(1):277-290, DOI 10.1016/j.jpowsour.2007.04.059

Hinebaugh J, Bazylak A (2010) Condensation in PEM Fuel Cell Gas Diffusion Layers: A Pore Network Modeling Approach. J Electrochem Soc 157(10):B1382-B1390, DOI 10.1149/1.3467837

Islahuddin M, Janssen H (2016) Numerical estimation of isothermal moisture storage and transport properties. In: Grunewald J (ed) Proc. CESBP Cent. Eur. Symp. Build. Phys. BauSIM, Dresden, pp 301-308

Janssen H, Scheffler GA, Plagge R (2016) Experimental study of dynamic effects in moisture transfer in building materials. Int J Heat Mass Transf 98:141-149, DOI 10.1016/j.ijheatmasstransfer.2016.03.031

Jerauld GR, Scriven LE, Davis HT (1984) Percolation and conduction on the 3D Voronoi and regular networks: a second case study in topological disorder. J Phys C Solid State Phys 17(19):3429-3439, DOI 10.1088/0022-3719/17/19/017

Jivkov AP, Hollis C, Etiese F, McDonald SA, Withers PJ (2013) A novel architecture for pore network modelling with applications to permeability of porous media. J Hydrol 486:246-258, DOI 10.1016/j. jhydrol.2013.01.045

Lindquist WB, Lee SM, Coker DA, Jones KW, Spanne P (1996) Medial axis analysis of void structure in three-dimensional tomographic images of porous media. J Geophys Res Solid Earth 101(B4):82978310, DOI 10.1029/95JB03039

Mason G, Morrow NR (1991) Capillary behavior of a perfectly wetting liquid in irregular triangular tubes. J Colloid Interface Sci 141(1):262-274, DOI 10.1016/0021-9797(91)90321-X

Mayer RP, Stowe RA (1965) Mercury porosimetry-breakthrough pressure for penetration between packed spheres. J Colloid Sci 20(8):893-911, DOI 10.1016/0095-8522(65)90061-9

Parlar M, Yortsos YC (1988) Percolation theory of vapor adsorption-desorption processes in porous materials. J Colloid Interface Sci 124(1):162-176, DOI 10.1016/0021-9797(88)90337-2

Patzek T, Kristensen J (2001) Shape Factor Correlations of Hydraulic Conductance in Noncircular Capillaries: II. Two-Phase Creeping Flow. J Colloid Interface Sci 236(2):305-317, DOI 10.1006/jcis. 2000.7414

Pel L, Kopinga K, Brocken H (1996) Moisture transport in porous building materials. Heron 41(2):95-105

Piri M, Blunt MJ (2005) Three-dimensional mixed-wet random pore-scale network modeling of twoand three-phase flow in porous media. I. Model description. Phys Rev E 71(2):026301, DOI 10.1103/ PhysRevE.71.026301

Prat M (2011) Pore Network Models of Drying, Contact Angle, and Film Flows. Chem Eng Technol 34(7):1029-1038, DOI 10.1002/ceat.201100056

Princen H (1969a) Capillary phenomena in assemblies of parallel cylinders: I. Capillary rise between two cylinders. J Colloid Interface Sci 30(1):69-75, DOI 10.1016/0021-9797(69)90379-8

590 Princen H (1969b) Capillary phenomena in assemblies of parallel cylinders: II. Capillary rise in systems with more than two cylinders. J Colloid Interface Sci 30(3):359-371, DOI 10.1016/0021-9797(69) 90403-2 
Postprint: Islahuddin M. and Janssen H. 2019. Pore-structure-based determination of unsaturated hygric properties of porous materials. Transp Porous Med, 130:675.

https://doi.org/10.1007/s11242-019-01334-7

Princen H (1970) Capillary phenomena in assemblies of parallel cylinders: III. Liquid Columns between Horizontal Parallel Cylinders. J Colloid Interface Sci 34(2):171-184, DOI 10.1016/0021-9797(70) 90167-0

Qin C (2015) Water Transport in the Gas Diffusion Layer of a Polymer Electrolyte Fuel Cell: Dynamic Pore-Network Modeling. J Electrochem Soc 162(9):F1036-F1046, DOI 10.1149/2.0861509jes

Quenard D, Sallee H (1992) Water vapor adsorption and transfer in cement-based materials: a network simulation. Mater Struct 25(9):515-522, DOI 10.1007/BF02472447

Roels S, Carmeliet J, Hens H (2003a) HAMSTAD WP1: Final report - Moisture transfer properties and materials characterisation (February):114

Roels S, Carmeliet J, Hens H (2003b) Modelling Unsaturated Moisture Transport in Heterogeneous Limestone. Transp Porous Media 52(3):333-350, DOI 10.1023/A:1023552011642

Roels S, Carmeliet J, Hens H, Adan O, Brocken H, Cerny R, Pavlík Z, Ellis aT, Hall C, Kumaran K, Pel L, Plagge R (2004a) A Comparison of Different Techniques to Quantify Moisture Content Profiles in Porous Building Materials. J Build Phys 27(4):261-276, DOI 10.1177/1097196304042117

Roels S, Carmeliet J, Hens H, Adan O, Brocken H, Cerny R, Pavlik Z, Hall C, Kumaran K, Pel L, Plagge R (2004b) Interlaboratory Comparison of Hygric Properties of Porous Building Materials. J Build Phys 27(4):307-325, DOI 10.1177/1097196304042119

Sahimi M (1993) Flow phenomena in rocks: from continuum models to fractals, percolation, cellular automata, and simulated annealing. Rev Mod Phys 65(4):1393-1534, DOI 10.1103/RevModPhys.65. 1393

Scheffler GA, Plagge R (2010) A whole range hygric material model: Modelling liquid and vapour transport properties in porous media. Int J Heat Mass Transf 53(1-3):286-296, DOI 10.1016/j. ijheatmasstransfer.2009.09.030

Silin D, Patzek T (2006) Pore space morphology analysis using maximal inscribed spheres. Phys A Stat Mech its Appl 371(2):336-360, DOI 10.1016/j.physa.2006.04.048

Valvatne PH, Piri M, Lopez X, Blunt MJ (2005) Predictive Pore-Scale Modeling of Single and Multiphase Flow. Transp Porous Media 58(1):23-41, DOI 10.1007/s11242-004-5468-2

Van De Walle W, Claes S, Janssen H (2018) Implementation and validation of a 3D image-based prediction model for the thermal conductivity of cellular and granular porous building blocks. Constr Build Mater 182:427-440, DOI 10.1016/j.conbuildmat.2018.06.105

Vogel HJ, Roth K (2001) Quantitative morphology and network representation of soil pore structure. Adv Water Resour 24(3-4):233-242, DOI 10.1016/S0309-1708(00)00055-5

${ }_{625}$ Vorhauer N, Metzger T, Tsotsas E (2010) Empirical Macroscopic Model for Drying of Porous Media Based on Pore Networks and Scaling Theory. Dry Technol 28(8):991-1000, DOI 10.1080/07373937. 2010.497088

Wilkinson D, Willemsen JF (1983) Invasion percolation: a new form of percolation theory. J Phys A Math Gen 16:3365-3376

Yiotis AG, Tsimpanogiannis IN, Stubos AK, Yortsos YC (2006) Pore-network study of the characteristic periods in the drying of porous materials. J Colloid Interface Sci 297(2):738-748, DOI 10.1016/j.jcis. 2005.11 .043 